Abstract

\title{
The Return of Metaphysics in the Theory of Subjective Pregnances ${ }^{+}$
}

\section{Rainer E. Zimmermann}

University of Applied Sciences, Munich 80636, Germany; rainer.zimmermann@hm.edu; Tel.: +49-089-1265-4346

+ Presented at the IS4SI 2017 Summit DIGITALISATION FOR A SUSTAINABLE SOCIETY, Gothenburg, Sweden, 12-16 June 2017.

Published: 9 June 2017

In his work on what he called "Semiophysics" at the time (1988), René Thom introduced the cognitive viewpoint into physics by trying to develop a science of meaning on the line of his "catastrophe theory" which was essentially a theory of physical morphogenesis. The basic intention was to reconcile modern mathematics and physics with the traditional conception of natural philosophy. The recent developments in quantum physics and their philosophical interpretations lead back to this basic idea. It is thus shown how the formalized language of mathematics cannot only be combined with spatio-temporal aspects of the physical world, but can also serve the definitory precision of concepts such as matter and information, respectively.

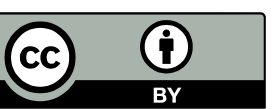

(C) 2017 by the author. Licensee MDPI, Basel, Switzerland. This article is an open access article distributed under the terms and conditions of the Creative Commons Attribution (CC BY) license (http://creativecommons.org/licenses/by/4.0/). 